\title{
HeRANÇAS MEMORIAIS EM TEXACO
}

\author{
MEMORY INHERITANCE IN TEXACO \\ João Luiz Peçanha Couto
}

Universidade Federal Fluminense

Niterói - RJ

\section{Resumo}

$\mathrm{O}$ presente artigo analisa as interaçóes entre a memória e as relaçóes familiares entrevistas no romance Texaco, do escritor martinicano Patrick Chamoiseau. A obra referida foi construída com base nas memórias de Marie-Sophie Laborieux, a protagonista, herdadas de seu pai Esternome. Tais memórias serão responsáveis pela busca e pela edificação do bairro Texaco, ideia-sonho de cidade concretizada a custo por seus primeiros moradores, Marie-Sophie à frente. A partir dessa premissa, é proposta a noção de transmemória para auxiliar na compreensão da importância das relaçóes entre a memória, sua transmissão e o afeto na literatura.

Palavras-chave: Memória, Espaços periféricos, Modernidades alternativas.

\section{Abstract}

This article seeks to analyze interactions between family relationships and memory perceived in the novel Texaco, written by Martinican novelist Patrick Chamoiseau. The novel was constructed around main character Marie-Sophie Laborieux's memories, which she inherited from Esternome, her father. Such memories will prompt the search for and building of the Texaco neighborhood, a dream dwelling space made a reality by the efforts of its first inhabitants, with MarieSophie at the helm. From this premise, the notion of transmemory is proposed to assist in understanding the importance of the relationship between memory, its transmission and affection in literature.

Keywords: Memory, Peripheral areas, Alternativa modernities.

\section{Resumen}

Este artículo analiza las interacciones entre la memoria y las relaciones familiares que aparecen en la novela Texaco, del escritor martiniqueño Patrick Chamoiseau. La obra se construye a partir de los recuerdos de Marie-Sophie Laborieux, la protagonista, heredados de su padre Esternome. Tales memorias serán responsables por la búsqueda y la construcción del barrio de Texaco, idea/sueño de ciudad, concretizada por el esfuerzo de sus primeros habitantes, Marie-Sophie al frente. A partir de esta premisa, es propuesta la noción de transmemoria para comprender la importancia de la relación entre la memoria, su transmisión y el afecto en la literatura.

Palabras claves: Memoria, Espacios periféricos, Modernidades alternativas. 
Pretendo levantar provocaçóes acerca da ideia de memória como instituidora do espaço literário, sobrepujando conceitos canônicos como a representação (pois, no trabalho mnêmico, a mimese é imperfeita) e a identidade (pois, como essência, foi suplantada pelas pequenas emergências de fundo comunitário). Como chave de apoio para a proposta teórica, sugiro a análise do romance Texaco (1993), do escritor martinicano Patrick Chamoiseau.

Quando se refere ao esforço de retorno de Ulisses a Ítaca, Jean Marie Gagnebin (2006) pontifica primeiramente que a batalha mais fulcral da memória é contra o esquecimento. O esquecimento que, segundo Augé (2015), é tão necessário à sociedade quanto ao indivíduo. Nesse sentido, a luta maior do Odisseu não é somente pela manutenção da memória, mas igualmente da palavra, dos cantos, das histórias e dos mitos inventados pelos homens para a rememoração de seu passado e para não se esquecerem do futuro. É a partir da escrita, desse "túmulo de palavras", que o homem se perpetua, num mesmo movimento afastando-se da morte e do esquecimento: “(...) a escrita foi, durante muito tempo, considerada o rastro mais duradouro que um homem pode deixar, uma marca capaz de sobreviver à morte de seu autor e de transmitir sua mensagem" (GAGNEBIN, 2006: 112). Antiga, essa aliança entre a morte e o esquecimento liga-se a outra, tão ou mais fundamental para a presente discussão: a relação entre os complementares vida e memória, sendo esta a fiel depositária de rastros que mantêm viva aquela.

(...) este rastro privilegiado que os homens deixam de si mesmos, desde as estelas funerárias até os e-mails efêmeros que apagamos depois do uso - sem esquecer, naturalmente, os papiros, os palimpsestos, a tábua de cera de Aristóteles, o bloco mágico de Freud, os livros e as bibliotecas: metáforas-chave das tentativas filosóficas, literárias e psicológicas de descrever os mecanismos da memória e do lembrar (GAGNEBIN, 2006: 111).

O mesmo Ulisses também é tratado por Maurice Blanchot em seu $O$ livro por vir (2005). Para o pensador francês, o Odisseu alegoriza o esforço empreendido pelo saber ocidental para reempoderar sua racionalidade frente às forças do mistério, representadas pelas sereias do Canto IX da Odisseia, e sobretudo por seu canto - verdadeiro trabalho de desfazimento das certezas da racionalidade do Ocidente. A esse respeito, Kafka afirma que as sereias possuíam uma arma ainda mais potente que o seu canto - era o seu silêncio. Silêncio que não será de fundo a matéria-prima deste texto, mas seu reino: a memória, articulada às lembranças familiares retidas por herança e a um espaço estético precário e excessivo: Texaco ${ }^{1}$.

\footnotetext{
${ }^{1}$ A palavra "Texaco", sempre que grafada em itálico, referir-se-á à obra de Patrick Chamoiseau. Entretanto, se grafada em fonte normal, será uma referência à comunidade existente na periferia de Fort de France, Martinica.
} 
De que se tratam as cidades crioulas espalhadas pelo planeta? São lugares onde a presença do poder público perde potência na mesma medida em que os cidadáos daqueles espaços precários veem-se obrigados a refabular a própria existência, por vezes utilizando-se de artimanhas pouco íntimas da legalidade. Texaco, Fort de France, Martinica: o genoma urbanístico desse espaço deixa-se contaminar por formas de compreensão social novas e diferentes, contando com uma organização social tão dinâmica a ponto de admitir, muitas vezes concomitantemente, demoliçôes e incêndios seguidos de reconstruçóes que, à moda de um tumor incontrolável, alastram-se, transformando-se em bairros de lata que se transmutam em bairros de madeira ou argamassa que, após nova leva de incêndios, demoliçôes ou expulsôes, são seguidos por novas reconstruçóes, tão anônimas, rápidas e pandêmicas quanto as vidas daqueles que as perpetraram. Espaços precários como Texaco possuem uma dinâmica urbanística muito mais ativa que os espaços de conformidade urbana tradicional, amplamente amparados pela lei. Sua modernidade é alternativa, como são dessemelhantes suas regras organizacionais quando contrapostas às dos espaços hegemônico-modernos. Desse modo, um espaço como Texaco injeta modernidades alternativas tumorizantes nas células sanguíneas da modernidade clássica e triunfalista, sã, contaminando-a com a nova lógica daqueles espaços políticos pós-coloniais, emergentes e compósitos presentes no atual processo globalizante. Bill Ashcroft confirma essa proposição quando diz que "a globalização pode ser caracterizada como uma multiplicidade de suas modernidades, e as teorias pós-coloniais podem oferecer um gesto de compreensão desse fenômeno" (ASHCROFT, 2009: 81).

Nesses espaços, memória e verdade histórica não se intimizam, afirmação que nos leva a Benjamin (1994), para quem a articulação histórica do passado não significa afirmar seu conhecimento tal como foi, mas apoderar-se de uma lembrança. Podendo referenciar falsas lembranças, porque imprecisas ou incompletas, a memória assemelha-se aos antigos métodos de observação de um objeto, não se constituindo, por isso, uma correspondência direta com o vivido, mas ao "tecido de sua rememoração, o trabalho de Penélope da reminiscência" (BENJAMIN, 1994: 37). A analogia dos caminhos da memória com o trabalho de artesã da esposa do Odisseu permite o resgate etimológico do vocábulo "texto", identificando-o com "tecido", trama constituída fragmentariamente por lembranças, reminiscências e deslizes, falseamentos que podem e devem ser recerzidos pelo trabalho estético textual. Em outras palavras, isso empodera a proposição de que a memória deva ser compreendida como a construtora preferencial de toda narrativa ficcional.

A palavra poética representa o ponto a partir do qual a memória "deixa emergir o tempo do esquecimento, liberando o que ficou retido nos desvãos da história" (BERND, 2013: 97). Isso empresta poder à argila 
literária, dotando-a de um poder de resgate mnêmico unicamente potente nos produtos estéticos, pois “(...) somente as sensibilidades compartilhadas e as cumplicidades delimitam o espaço privilegiado onde os nós da memória poderão enfim ser desatados" (BERND, 2013: 97). Conforme a autora, a memória é (re)constituída pela via do pensamento crítico, uma vez que "Uma lembrança é um diamante bruto que precisa ser lapidado pelo espírito. Sem o trabalho da reflexão e da localização, ela seria uma imagem fugidia" (BOSI, 1994: 21).

Como falamos de etimologia, lembro que, ao tocarmos a palavra "memória", resgatamos imediatamente o termo "lembrar", o que nos leva às palavras iniciais deste artigo: lembrar de um algo demanda esquecer outro algo. Ou: para lembrar, à semelhança do ancestral princípio da Física que reza que dois corpos não podem ocupar o mesmo lugar no espaço, o homem esquece. Por seu turno, Eclea Bosi (1994) remonta as origens do verbo "lembrar": do francês, "souvenir", que tem que ver com um movimento de vir de baixo: sous-venir, ou fazer com que algo que estava oculto venha à tona.

Igualmente o senso de realidade, aquelas crenças naquilo que designamos como "real", pode ser considerado como uma redução de uma suposta realidade-totalidade indefensável por inalcançável. Se a realidade é finita, vez que se encarcera na própria necessidade de responder às certezas tramadas para a sua constituição, a narrativa de ficção liga-se ao rascunho, ao instável e ao indiscernível que jaz em todo gesto de fabulação do real, uma vez que "um acontecimento vivido é finito, ou pelo menos encerrado na esfera do vivido, ao passo que o acontecimento lembrado é sem limites, porque é apenas uma chave para tudo o que veio antes e depois" (BENJAMIN, 1994: 37).

2

Em espaços como Texaco ou qualquer comunidade pós-colonial do globo, importa que os marcos identitários deixam de ser táo-somente espaciais para se tornarem interacionais. Isso questiona na origem conceitos essencialistas, tais como comunidade imaginada, Estado e nação, além de exigir que se considere aqueles espaços de precariedade sob a ótica de suas diversas subjetividades em interação: na pós-modernidade em que ora flutuamos, $a$ subjetividade é a força motriz de qualquer coisa que se assemelhe à identidade cultural, porque foi dispersada há dois, três séculos e reconstituída sob normas créole. Ashcroft afirma que

Violentamente capturados e transportados, dispersos pelo Novo Mudo, colocados em plantations com falantes de diferentes línguas, destituídos não apenas de uma língua comum, mas de história e de origem, eles eventualmente 
conseguirão articular [constituir] sua [ideia de] modernidade pós-colonial (ASHCROFT, 2009: 88).

Os espaços precários pós-coloniais mantêm em seus meandros os rastros de duas modernidades, de duas formas diferentes de uso urbano, "vivendo entre a assimilação do modelo original, isto é, entre o amor e o respeito pelo já-escrito, e a necessidade de produzir um novo texto que afronte o primeiro e muitas vezes o negue" (SANTIAGO, 2000: 23). Assim, o espaço, tratado na obra Texaco, de Patrick Chamoiseau, revela-se um lugar - pois é composto por memórias e corpos que movem intençôes, sendo histórica e socialmente significativo. Nele, o tempo histórico é revelado pela ação do homem - mais precisamente na franja que comunga o interior e o exterior humanos: a paisagem, articulação da cultura com um lugar significado na memória pela via do afeto, sobretudo aquele alimentado pelas relaçóes familiares.

A escrita - identificada com o grafado e o cristalizado, com a rigidez e a permanência, com o Mesmo instituidor, com o poder institucionalizado, com o longo braço europeu nas novas terras, arremedo de eternidade imposto pela modernidade ocidental, livrando suas empresas do caudal perigoso das metamorfoses da História - tem como contrapalavra em Texaco, potente, a fala, pertencente ao reino do "inseguro e precário" (RAMA, 1985: 29). Ajuntando os dois domínios a seu modo, a protagonista Marie-Sophie Laborieux mixa os limites desta oposição. Vejamos: mesmo que constantemente empodere a palavra de homens entendidos pelos olhos ocidentais como "incultos" (os mentôs, Papa-Totone etc.), seus escritos (diários grafados anos a fio por MarieSophie) acabam por reafirmar o poder cristalizador da escrita (a rainha dos magmas), coroando-a frente à sua suposta oponente (a oralidade, a rainha dos ventos). Esta última, no fim, "rifa" sua oponente, pois o "nome secreto" não será dado a conhecer até a morte de Marie-Sophie, "nome secreto" este cativo da oralidade mesma que o pariu.

O noutéka dos morros foi a estratégia utilizada para entronizar de sentidos vários, afetivamente significativos, os espaços de Texaco (a Martinica, Saint-Pierre, Fort-de-France, o espaço Texaco): o nós mágico da obra auxilia a protagonista a recerzir suas memórias com as de Esternome, do Urbanista e da Martinica, ressignificando a luta daquela coletividade e construindo o próprio movimento da narrativa, tecida por aqueles rastros, reunidos pela contadora Marie-Sophie.

No quesito espaço, Texaco desenvolve-se em um cenário de precariedade em que reinam sua desumanidade e suas impossibilidades (de florescimento poético, de vivências estéticas). Ali, onde a brutalidade da canis vitae enfraquece a possibilidade de sobrevivência de um rastro poético, a memória e o afeto, vitaminados pelas relaçóes familiares entre Marie-Sophie e Esternome, surgem como alternativa para seu resgate. 
A linguagem hiperbólica de Texaco excede a própria língua em que é escrita, graças a certa braconagem (HAREL, 2005) perpetrada pelo créole: ali existe a astúcia de romper a norma de dentro dela, à semelhança do vírus que adentra um corpo são: depois de morto o invasor, o corpo mantém em si sinais do microorganismo (vírus) que o contaminou. A saúde futura do corpo depende da memória que mantém de sua quase morte. Da mesma forma, no romance de Patrick Chamoiseau, o francês castiço e continental é testado em seus limites, é extrapolado e esgarçado por uma língua astuta e perniciosa, o créole. Podemos supor que esse ato "subversivo" do créole tenha sido perpetrado como forma de inscrever as "pequenas epopeias" daqueles seres dejetos-precários na grande linha do tempo da história tradicional, inserindoas naquela "grande narrativa" ocidental, o que nos permite apresentar a obra Texaco como trabalho de resgate da memória de personagens proprietários daquelas "pequenas epopeias" a partir dos vestígios memoriais.

A escrita da história só passou a aceitar também o ponto de vista de quem sempre a perdeu no último terço do século XX. Narrada anteriormente apenas por quem se mantinha no topo da pirâmide hegemônica do mundo, a grafia histórica tradicional apresentava um problema metodológico-analítico que impossibilitava outras leituras, pois "Esta cosmologia de 'única narrativa' oblitera as multiplicidades, as heterogeneidades contemporâneas do espaço. Reduz coexistências simultâneas a um lugar na fila da história" (MASSEY, 2013: 24). Dessa forma, se Pierre Nora (1997) estiver certo, quando afirma que a história e a literatura constituem as duas formas de legitimaçáo da memória, o trabalho desempenhado por aqueles excessos linguísticos do créole com o qual Texaco foi escrito assinala a inscrição daquelas vozes nascidas das "pequenas epopeias", como destituidoras do discurso histórico tradicional.

Marie-Shopie Laborieux, a criadora do espaço de memórias de Texaco, é assim descrita no último capítulo da obra: “(...) uma velha negra cabra, muito alta, muito magra, com um rosto grave, solene, e olhos imóveis. Jamais eu havia percebido tanta autoridade profunda irradiar de alguém" (CHAMOISEAU, 1993: 342). Em seguida, a própria protagonista sugere uma possível chave de leitura para a obra do escritor martinicano: "perseguira a palavra do pai, e as palavras raras de Papa Totone, e os fragmentos de nossas histórias que o vento levava assim, ao sabor das terras" (CHAMOISEAU, 1993: 343). Tal chave de análise empodera a opção de, a partir da memória, reconstruir e compreender aquele espaço.

A "pobre epopeia" de Marie-Sophie foi grafada graças à herança de uma ideia-sonho semeada por Esternome, seu pai e único representante vivo de 
sua família: a ideia da Cidade, necessariamente companheira de memórias e afetos, de precariedades e esquecimentos. Não é a busca da cidade ocidental, moderna, higienizada, radicular e baseada em códigos escritos, mas daquela Cidade ágrafa criada a partir do binômio palavra-vento, não asseverada, inflada de sopros contados e recontados boca a boca e descosturada da temporalidade careta da História tradicional. Uma Cidade em que se possam afirmar as palavras de quem nunca as viu e nem sequer sonhou escutadas. A Cidade das memórias e dos afetos que mistura as línguas em suas esquinas que fogem do ângulo reto cartesiano da cidade moderna para contar histórias "pouco nobres" de uma pós-colonialidade extravasada de (nas) margens. Era Texaco.

Meu interesse pelo mundo resumia-se a Texaco, minha obra, nosso bairro, nosso campo de batalha e de resistência. Ali levávamos adiante uma luta pela Cidade, começada já havia mais de um século. E essa luta supunha um enfrentamento no qual estariam em jogo nossa existência ou nosso fracasso definitivo (CHAMOISEAU, 1993: 33).

Isso confirma a ideia de Marie-Sophie, de que a memória e a palavra de poder tornem-se pontos de apoio para a compreensão da realidade vivida por ela e por Esternome - e da obra: é a partir da palavra que a memória de Esternome se imiscui com as rememoraçóes que brotam da boca e da pena de Marie-Sophie, construindo a ideia de Cidade, a ideia-Cidade-crioula que parirá Texaco - o espaço-dejeto habitado por dejetos da modernidade. MarieSophie identifica-se com os velhos narradores que perpetuam experiências, muitas delas vinculadas ao trabalho que ela ou Esternome exerciam à época:

(...) os velhos narradores (...) estâo vinculados por uma noção tấo entranhada do trabalho e das relaçóes sociais que, aos poucos, configuram, de fato, uma classe. Duas vezes oprimida: pela dependência social e pela velhice (...) (BARBOSA, 1994: 11-12).

Pois o trabalho ressignifica o mundo - espécie de dispositivo ativador da memória que permite a construção de qualquer narrativa: "Caminhar e ver confundem-se nos confins da lembrança: o tempo de lembrar traduzse, enfim, pelo tempo de trabalhar. Por isso, sem a memória do trabalho a narração perderia a sua qualidade épica" (BARBOSA, 1994: 15).

A Cidade-sonho transubstancia-se no "nome secreto" de Marie-Sophie, substantivo mítico revelado apenas nos estertores da obra:

Disse-lhe [a Cristo, o Urbanista], para terminar, que me sentia velha. Que um dia, quando ele viesse, eu não estaria mais lá. Pedi-lhe um favor, Oiseau de Cham, favor que eu gostaria que você anotasse e lhe lembrasse: que jamais em tempo algum, nos séculos e nos séculos, não se tire desse lugar o nome de 
TEXACO, em nome de meu Esternome, em nome de nossos sofrimentos, em nome de nossos combates, segundo a lei intangível de nossas mais elevadas memórias e essa, bem mais íntima, de meu querido nome secreto que confesso-lhe finalmente - não é outro senão este (CHAMOISEAU, 1993: 337).

O Marcador de Palavras perpetrou um estratagema: deixar para o fim do livro a revelação que, como toda revelação, deve ser enunciada como palavra de poder. Exaurida a língua, a palavra prepondera em definitivo, tão logo terminada a contação da epopeia.

Mas antes da enunciação do nome secreto, Marie-Sophie havia que transformar aquela ideia-sonho em ideia-Cidade. Nesse sentido, a ladeira foi o espaço primordial para que a protagonista construísse sua Texaco - a partir daquela utopia de Cidade herdada de Esternome. Na ladeira, foi gestado primeiramente o DNA de Texaco, preenchido com teimosia quase poética e medos quase prosaicos, persistência e descobertas, acordos braconeiros e enfrentamentos com almas despertas e unhas cravando-se nas palmas úmidas de mãos calejadas.

Ainda a respeito da influência da ideia-sonho herdada de seu pai, importa lembrar que, entendido como o suporte de rememoraçóes de MarieSophie, Esternome engendra em si as funções do lembrar, tradicionalmente designadas aos velhos.

A função social do velho é lembrar e aconselhar - memini, moneo - unir o começo e o fim, ligando o que foi e o porvir. Mas a sociedade capitalista impede a lembrança, usa o braço servil do velho e recusa seus conselhos. (...) A sociedade capitalista desarma o velho mobilizando mecanismos pelos quais oprime a velhice, destrói os apoios da memória e substitui a lembrança pela história oficial celebrativa (CHAUÍ, 2012: 18).

Já bastante idosa nas últimas páginas de Texaco, Marie-Sophie vê suas lembranças recentes desvanecendo-se, mas a memória dos acontecimentos pretéritos mantém-se:

Minha memória já não era tão boa para se lembrar de ontem. Em compensação, passava o tempo a vasculhar os fundos de minha vida, a remexer nos restos de recordaçóes perdidas, cuja passagem imprevista infligia-me o olho móvel dos ratos presos numa rede. Comecei a me lembrar, a viver devaneios de odores... (...) minha vida não era mais do que uma mala de sírio aberta numa calçada. Eu vagava por entre seu conteúdo, asfixiada pela poeira dos anos (CHAMOISEAU, 1993: 328).

Esternome cumpre, na maior parte do romance, a função do "velho" de Marie-Sophie, sua memória, a memória da Martinica, que confessa, prenhe 
de delicadezas, sentindo-se envelhecido: "Velhice, Marie-Sophie, é como uma lenta surpresa" (CHAMOISEAU, 1993: 152). É a partir do que ele conta que a filha reconstrói o passado e confere certezas ao presente. É sua luta, tanto quanto é a luta de Marie-Sophie, quando se vê frente a Cristo, no primeiro encontro dos dois. A certeza de que seu "suporte material da memória" seria a causa do ganho ou da perda de Texaco surge na fala da narradora:

Então, respirei fundo: de repente, compreendi que era eu, em volta daquela mesa e de um pobre rum envelhecido, tendo como única arma a persuasáo de minha palavra, que devia travar sozinha - na minha idade - a decisiva batalha pela sobrevivência de Texaco (CHAMOISEAU, 1993: 34).

A possibilidade de se compreender a memória que aqui proponho irmana-se com a competência que um espaço possui para transitar afetos. Esse entendimento passa pelo conceito glissantiano de paisagem (GLISSANT, 2011): um espaço afetiva e culturalmente significado. Se a definição clássica grafada por Ezra Pound reza que a literatura é a linguagem carregada de significados, a paisagem espelha a máxima: a paisagem é o espaço carregado em sua máxima potência de sentidos culturais e, portanto, afetivos.

4

Maurice Halbwachs (1990) consigna o que chama de quadros sociais da memória como os suportes fundamentais sobre os quais se assenta sua concepção de memória. Para esse autor, a memória se constituiria por hierarquização: a memória individual "depende do seu relacionamento com a família, com a classe social, com a escola, com a Igreja, com a profissão" (BOSI, 1994, p. 54). Graças a este irmanamento social da memória, ela não se trama no sonho, mas no trabalho, na lida em grupo - o que faz considerar o trabalho como ponto de apoio para as lembranças: "Bela memória é ofício", escreve Marie-Sophie (CHAMOISEAU, 1993: 47).

(...) o que rege, em última instância, a atividade mnêmica é a função social exercida aqui e agora pelo sujeito que lembra. Há um momento em que o homem maduro deixa de ser um membro ativo da sociedade, deixa de ser um propulsor da vida presente do seu grupo: neste momento de velhice social resta-lhe, no entanto, uma função própria: a de lembrar (BOSI, 1994: 63).

Nesse sentido, Zilá Bernd (2013) propóe uma leitura do conceito de memória como processo não tendente a uma totalidade, mas "algo que se persegue e que se atinge sempre de forma fragmentária, inacabada, algo que se situa em um espaço intervalar entre memória e esquecimento" (BERND, 2013: 26). 
Assim, as lembranças se transmutam em memória graças aos afetos daquele que lembra. É patente a relação entre o florescimento do bairro Texaco e o ressurgimento das memórias da narradora:

Em meu espírito, tudo estava cada vez mais claro, uma lucidez solitária, e ver Texaco crescer aclarava em minha cabeça cada palavra de meu Esternome, esclarecia o mistério das palavras do preto velho da Doum (CHAMOISEAU, 1993: 285).

A memória de Marie-Sophie atrela-se às palavras e às rememoraçóes, suas e de seu Esternome, fazendo supor que a memória não é composta apenas pelas reminiscências do lembrante. Antes, é "palimpséstica”, justaposição quase geologicamente assentada de lembranças de primeira e segunda ordem, sociais e afetivas. A memória social mostra-se fecunda para registrar a importância do resgate dos vestígios do passado, como queria Benjamin (1994), iluminando o presente e apontando para o futuro. Já Maurice Halbwachs (1990) sublinha a importância do espaço para a compreensão dos fenômenos associados à memória coletiva. Neste ponto, cabe uma provocação um tanto abusada de minha parte.

Suponhamos um "pecado" (Engano? Deslize? Incoerência?) de Halbwachs: ter vinculado a memória social a um espaço supostamente inerte. Para o teórico dos quadros sociais da memória, somente o espaço seria estável o bastante para não se transformar e "envelhecer", para não perder nenhuma de suas partes constituintes. Assim, Halbwachs acreditava que o espaço constituía um elemento invariável, o que não me parece correto. A compreensão do espaço como elemento apolítico, como se fosse um "todo sem costuras" (MASSEY, 2013: 71), distante das contingências do mundo, como o monolito do filme 2001, uma odisseia no espaço, "permite a existência de apenas uma história, uma voz, uma posição do discurso" (MASSEY, 2013: 71). Portanto, proponho uma leitura do espaço como elemento histórico de potencial político, processual e prenhe de instabilidades, resultante de interrelações, como postula Doreen Massey, para quem

Ele [o espaço] modula nossos entendimentos do mundo, nossas atitudes frente aos outros, nossa política. Afeta o modo como entendemos a globalização, como abordamos as cidades e desenvolvemos e praticamos um sentido de lugar. Se o tempo é a dimensão da mudança, então o espaço é a dimensão do social: da coexistência contemporânea dos outros (MASSEY, 2013: 15).

Assim, o espaço não constitui lugar de negação do tempo e da história (ou da "estória", como ela grafa, haja visto o imenso potencial ficcional embutido em toda narrativa histórica), mas um lugar de negação de 
essencialismos identitários datados, onde se verifica a "existência coetânea de uma pluralidade de trajetórias, uma simultaneidade de estórias-até-agora" (MASSEY, 2013: 33). Esta concepção de espaço liga-o ao tempo e à dimensão de um futuro histórico que abraça as várias contranarrativas encontradas na pós-modernidade: "Para que o futuro seja aberto, o espaço também deve sê-lo" (MASSEY, 2013: 32).

Mas o espaço auxilia Halbwachs a compor seus "quadros sociais" da memória, onde lembranças individuais e coletivas são amalgamadas, aquelas devedoras destas:

Não é suficiente reconstituir peça por peça a imagem de um acontecimento do passado para se obter uma lembrança. É necessário que esta reconstrução se opere a partir de dados ou de noçóes comuns que se encontram tanto no nosso espírito como no dos outros, porque elas passam incessantemente desses para aquele e reciprocamente, o que só é possível se fizeram e continuam a fazer parte de uma mesma sociedade. Somente assim podemos compreender que uma lembrança possa ser ao mesmo tempo reconhecida e reconstruída (HALBWACHS, 1990: 34).

Para Halbwachs, a memória individual só é factível quando "nos colocamos no ponto de vista de um ou mais grupos e de nos situar novamente em uma ou mais correntes do pensamento coletivo" (HALBWACHS, 1990: 36). É uma resultante da memória coletiva. Mesmo que a vivência ou apreensão tenha sido individual, as reminiscências particulares tornam-se coletivas, pois são compostas por experiências de outrem, de uma comunidade ou sociedade. A uma memória “de primeira ordem”, constituída pelo indivíduo "lembrante" e por suas experiências pessoais, vem se somar outra memória, "de segunda ordem", de natureza social, que passa a ser agregada ao memorial de reminiscências daquele indivíduo. Na memória "de primeira ordem", as lembranças individuais se transmutam em memória sem intermediários. A memória "de segunda ordem", pertencente aos "quadros sociais" da memória coletiva, igualmente compóe a memória do lembrante, diferenciando-se das "de primeira ordem" por serem ligadas a certa "alteridade social".

Um suposto turista em viagem a Paris, que eventualmente tenha se negado a enfrentar a fila de entrada para o Louvre, pode afirmar aos amigos que se lembra mais dos cafés onde sentou ou das ruas aonde flanou do que de uma ou outra ala do Museu. Como o nosso turista não visitou o Louvre, não possui lembranças próprias dele, mas lembra-se, por exemplo, como uma memória "de segunda ordem", que as dimensóes do quadro mais famoso do museu não condizem com sua fama (pois sabe, segundo relatos entreouvidos por ele em uma antessala de dentista ou em elevadores, que a Mona Lisa é um quadro muito menor do que supóe alguém que não o tenha 
vislumbrado). Nosso turista anônimo, ao ter ouvido alguém comentar a respeito das dimensóes da obra de $\mathrm{Da}$ Vinci ou do gigantismo dos corredores do Louvre, incorporou tais informaçóes (a sua memória "de segunda ordem") ao seu memorial de lembranças, sem que, com isso, de fato tenha decidido enfrentar a malfadada fila ou tido aquela experiência.

Essa memória coletiva, ou memória social, adveio de comentários e experiências transmitidas (herdadas?) por pessoas que não necessariamente tivessem uma relação de afeto com o nosso turista. A informação entreouvida partiu de uma pessoa que eventualmente convive socialmente com ele - mas não necessariamente de alguém com quem ele (man)tenha uma relação de afeto.

A minha teimosia em propor um exemplo táo prosaico justifica-se: os quadros sociais da memória de Halbwachs, a meu ver, não dão conta de algumas situações. A proposição que formulo é a seguinte: o que é retido a longo prazo na memória "de segunda ordem" não é exclusivamente aquilo que se possa incluir no que Halbwachs designa como "quadro social", mas também algo que toca o afeto do lembrante e, portanto, aquilo que lhe é transmitido por alguém de seu memorial relacional afetivo pessoal. Se os quadros sociais apresentam uma alternativa sociológica (antropológica?) à chamada memória de segunda ordem, o que dizem das memórias de segunda ordem de fundo pessoal-afetivo?

Imagine-se um adulto anônimo que relatasse a experiência de, quando criança, ter tido uma boneca de pano permanentemente suja que, sempre que era lavada, provocava-lhe ataques de choro que só paravam quando a boneca era esfregada no chão até que tivesse de volta sua coloração cinzasujeira. A narrativa inventada acima resgata uma memória "de segunda ordem”, uma vez que não derivou de uma lembrança (experiência) própria da narradora. Até aqui, pode-se retrucar, não há diferenças perceptíveis entre esta rememoração e as rememoraçóes emergentes da memória coletiva de Halbwachs. Entretanto, há algo novo no trecho acima: tais rememoraçóes foram herdadas (por contágio, como toda memória de segunda ordem) de alguém com quem a narradora mantém estreita relaçáo afetiva (sua mãe).

Não se trata do conceito de pós-memória, resgatado por Beatriz Sarlo a partir de Marianne Hirsch (HIRSCH, 1997 apud SARLO, 2007). Tal conceito esgarça o sentido de memória social ao inseri-la na linha do tempo, pois refere-se à "memória da geraçấo seguinte àquela que protagonizou os acontecimentos” (BERND, 2013: 42):

Trata-se de uma dimensão mais específica em termos de tempo; mais íntima e subjetiva em termos de textura. Como pós-memória se designaria a memória da geração seguinte àquela que sofreu ou protagonizou os acontecimentos (quer dizer, a pós-memória seria a "memória" dos filhos sobre a memória dos pais) (SARLO, 2007: 91). 
A pós-memória se trata de uma memória derivada das lembranças de outrem - não de um quadro social, de uma comunidade ou sociedade. Entretanto, sobretudo por conta das razóes que levaram Beatriz Sarlo a se debruçar sobre os substratos da memória (um movimento de resgate das lembranças do período ditatorial argentino que então se fazia necessário), a pós-memória se propóe a representar estritamente aquele suporte de lembranças transmitido de uma geração a outra. Mais cirúrgica, a proposição ora apresentada visa focalizar tal "contágio de memórias" entre dois sujeitos em afeto, independentemente de vinculação a uma ou outra geração.

Uma memória (de segunda ordem) por contágio transpessoal - e aqui utilizo o termo "pessoal" por tocar duas subjetividades em afeto, o que exclui do recorte o contágio de memórias entre pessoas sem nenhuma relação afetiva. O contágio se dá de subjetividade para subjetividade, estando, necessariamente, estas duas subjetividades, em estado de afeto. Isso é o que aqui reivindico e designo para uma noção a ser aperfeiçoada adiante, de transmemória: uma memória de segunda ordem (obtida por contágio) cujo substrato, responsável por fazê-la aderir-se ao DNA mnemônico do "contagiado", é a relaçáo de afeto existente entre o conteur e o objeto do contágio (o ouvinte). Tal memória afetiva de segunda ordem foi designada como transmemória por necessariamente contar com tal contágio transpessoal (e aqui o sufixo trans presentifica a necessidade do trânsito entre as duas subjetividades). A transmemória, portanto, não se liga a um solo social, comunitário ou societal, mas à conjunção de duas subjetividades em afeto.

A noção de transmemória perpassará toda a obra de Patrick Chamoiseau: das quatro partes do romance (Tempos de palha, de madeira de caixote, de fibrocimento e de concreto), metade delas é devedora desse tipo de reminiscência, composta como um resgate da história de Esternome. Esternome não se lembra das agruras vividas por seu pai trancafiado na masmorra, nem de tê-lo visto envenenando animais. Marie-Sophie não se lembra do dia em que Esternome, com modos de zumbi de tristezas, devassa, em busca de sua Ninon, os detritos escombrosos de uma Saint-Pierre lambida pelos engulhos de fogo do Mont Pellè (“(...) o incêndio contido no morro, como um soluço amordaçado à beira da explosão sanguinária, em busca de uma ignição que se esquiva e se desconhece" (CÉSAIRE, 2012: 13).) Ela também não se recorda dos ângulos retos das dezenas de casas erguidas por seu pai ou do ciúme que Esternome sentiu quando percebeu que Ninon fugira com o tocador de mandolina. Em todos esses casos, a lembrança pertence a "um outro".

Tanto quanto qualquer rememoração, a transmemória não se pretende verdadeira: ajuntamento de lembranças e esquecimentos, depósito de detritos lembrados, com suas rupturas e invençóes, voluntárias ou não, não relembra um mundo tal qual era, mas fabula-o. Em seu movimento de não desejar ser 
verdade, pode acabar sendo uma dentre todas as já contadas. Já foi dito que as transmemórias compóem metade da obra de Patrick Chamoiseau. Tanto ou mais fundamentais que as memórias de primeira ordem de Marie-Sophie; que as memórias coletivas que ela ou seu pai recolheram ao longo da vida; que as histórias contadas por Ti-Cirique ou Papa Totone; que os relatos, entre poéticos e proféticos, do Urbanista, as transmemórias são, em última análise, responsáveis por grande parte da beleza hiperbólica e redundante da narrativa de Texaco, obra que reafirma tacitamente a literatura como empresa de resgate daquilo que pode ser esquecido.

\section{Referências bibliográficas}

ASHCROFT, Bill. "Alternative modernities: globalization and the post-colonial", ARIEL: A Review of International English Literature, Baltimore, Maryland. The Johns Hopkins University Press, 2009: 81-105.

AUGÉ, Marc. Por uma antropologia da mobilidade. Maceió: EDUFAL / UNESP, 2010.

BARBOSA, J. A. “Uma psicologia do oprimido”. In: BOSI, Ecléa. Memória e sociedade: lembrança de velhos. São Paulo: Companhia das Letras, 1994.

BENJAMIN, Walter. Magia e técnica, arte e politica: ensaios sobre literatura e história da cultura. Trad. Sérgio Paulo Rouanet. 7a. ed. São Paulo: Brasiliense, 1994.

BERND, Zilá. Por uma estética dos vestígios memoriais. Belo Horizonte: Fino Traço, 2013.

BLANCHOT, Maurice. O livro por vir. Trad. Leyla Perrone-Moisés. São Paulo: Martins Fontes, 2005.

BOSI, Ecléa. Memória e sociedade: lembranças de velhos. 17a. ed. Sáo Paulo: Companhia das Letras, 1994.

CÉSAIRE, Aimée. Diário de um retorno ao país natal. Trad. Lilian Pestre de Almeida. São Paulo: EDUSP, 2012.

CHAMOISEAU, Patrick. Texaco. Trad. Rosa Freire D’Aguiar. São Paulo: Companhia das Letras, 1993.

CHAUÍ, Marilena. "Apresentação". In: BOSI, E. Memória e sociedade: lembranças de velhos. 17a. ed. Sáo Paulo: Companhia das Letras, 1994.

GAGNEBIN, J. M. Lembrar escrever esquecer. São Paulo: 34, 2006.

GLISSANT,Édouard. Poética da Relação. Trad. Manuela Mendonça. Porto: Sextante, 2011. 
HALBWACHS, Maurice. A memória coletiva. Trad. Laurent Léon Schaffter. São Paulo: Vértice, 1990.

HAREL, Simon. "Braconagem: um novo modo de apropriação do lugar?". Interfaces Brasil / Canadá, Rio Grande: UFPel, 2005: 211-230.

HIRSCH, Marianne. Family frames: photography, narrative and postmemory. Cambridge (Mass.) e Londres: Harvard University Press, 1997.

MASSEY, Doreen. Pelo espaço: uma nova política da espacialidade. Trad. Hilda Pareto Maciel e Rogério Haesbaert. 4a. ed. Rio de Janeiro: Bertrand Brasil, 2013.

NORA, Pierre. Les lieux de mémoire. Paris: Gallimard, 1997.

RAMA, Angel. A cidade das letras. Trad. Emir Sader. São Paulo: Brasiliense, 1985.

SANTIAGO, Silviano. Uma literatura nos trópicos. Rio de Janeiro: Rocco, 2000.

SARLO, Beatriz. Tempo passado: cultura da memória e guinada subjetiva. Trad. Rosa Freira d'Aguiar. São Paulo: Companhia das Letras, 2007.

Joáo Luiz Peçanha Couto. É Doutor em Literatura Comparada pela UFF, Mestre em Literatura (Estudos Comparados) pela Universidade de São Paulo (USP) e Licenciado em Letras (Português e Inglês). Professor nas Faculdades Integradas Vianna Junior. Como pesquisador atua nos seguintes temas: literaturas contemporâneas periféricas, modernidades alternativas pós-coloniais, literatura africana em língua portuguesa, espaços precários da pós-modernidade, filosofia e cinema em diálogo com a literatura. E-mail: joaoluizpecanhacouto@gmail.com 